\title{
War with Outsiders Makes Peace Inside*
}

\author{
JOHANNES MÜNSTER \\ Free University of Berlin
}

KLAAS STAAL

University Bonn and IIW

This article presents a new theoretical perspective on the diversionary use of force. Players are partitioned into groups and choose how to allocate their resources to production, fighting against other groups, and fighting internally. The model gives a rationalist explanation of the group cohesion effect: when there is a lot of fighting between groups, there is less internal fighting. In equilibrium, players choose sufficiently high external conflict in order to avoid internal conflict. In contrast with the existing literature, this diversionary use of force takes place even though there is no asymmetric or incomplete information.

KEYWORDS: diversion, conflict, group cohesion effect, war

\footnotetext{
"The relation of comradeship and peace in the we-group and that of hostility and war towards the other-groups are correlative to each other. The exigencies of war with outsiders are what make peace inside." (Sumner, 1906: 12)
}

\section{Introduction}

The idea of diversionary wars figures prominently in many historical and political writings. Yet, its viability is debated, both empirically and theoretically. This article presents a new theoretical perspective on the diversionary use of force. We formalize the idea that diversionary wars are based on the so-called "group cohesion effect" that external conflict mitigates internal conflict, which is nicely expressed by William Sumner in our opening quote.

\footnotetext{
* We would like to thank Glenn Palmer, the anonymous reviewers of CMPS, and participants of the Jan Tinbergen Peace Science Conference 2006 in Amsterdam and the Peace Science Society International Conference 2007 at the University of South Carolina. We are also grateful to Helmut Bester, Roy Gardner, Kai Konrad, Daniel Krähmer, Robert Nuscheler, Patrick Rossol, and Dorothee Schmidt for helpful comments. Financial support from the German Research Foundation through SFB/TR15 is gratefully acknowledged. Johannes Münster gratefully acknowledges financial support from the Stuart A. Bremer award.
} 
Our model captures four main ideas. (i) Property is insecure: by investing resources in guns, it is possible to appropriate output from others. Moreover, players are partitioned into groups, where a group may represent a country or an ethnic group. Players have three activities: fighting against the outsiders, fighting against the insiders, and production. (ii) Players have limited resources. For example, resources used for production cannot be used for fighting, which is the usual trade-off between guns and butter. In addition, resources used for internal fighting cannot simultaneously be used against the outsiders and vice versa. (iii) Winning against insiders does not help if one loses against the outsiders - and vice versa. (iv) Decisions on external conflict are taken by a different type of decisionmaking process than decisions on internal conflict. Decisions on external conflict are collective decisions, taken by some political process within each group. In contrast, decisions about production and internal conflict - say, how hard to work, and whether or not to join a rebellion - are typically taken individually.

We study a two-stage model where in the first stage, groups decide how much to invest into fighting against the other groups. Investing more in the external conflict increases the group's share of total output. However, it also implies that the group's members have fewer resources available in the second stage. In stage 2, players individually decide how to allocate their remaining resources to internal fighting and production. Here, each player faces the classic trade-off between guns and butter: investing more into internal fighting increases the player's share, but has the opportunity cost of decreasing total output, since the resources invested in internal fighting can no longer be used for production. The equilibrium amount of internal fighting depends crucially on the tightness of the budget constraints. In particular, if players have few resources available in stage 2 , there will be only little or no internal fighting in stage 2 .

Now consider the incentives of a group in stage 1. Investing into external fighting increases the share of the group at the expense of the other groups. However, any resources invested into external fighting can no longer be used for production or internal fighting. Thus the group will take into account that its decision in stage 1 has an impact on the tightness of the budget constraints in stage 2 , and thereby on the equilibrium amount of internal fighting. The incentives to fight against the other groups thus depend, inter alia, on the effect of tighter budgets in stage 2. More external fighting could lead to less production, in which case there is a trade-off between external fighting and production. However, if more external fighting only reduces internal fighting, without decreasing production, then spending on external fighting increases the group's share without decreasing output, and therefore is clearly beneficial for the group.

We show that in our model, in equilibrium, groups always spend a sufficient amount on external fighting such that no internal fighting occurs. The individuals within a group have two benefits from this: they are no longer wasting resources in fighting internally, and by fighting the outsiders they increase their share at the expense of the other groups. Of course, from the perspective of all individuals, having no conflict at all would be even better; but if property is insecure, this is not an equilibrium. The intensity of external conflict is driven by the consideration that internal conflict should be avoided. A higher insecurity of property within groups, 
which ceteris paribus would imply higher incentives to fight internally, thus only leads to more external conflict.

As a robustness check, we also consider the case where all decisions are taken individually, including decisions about external conflict. We show that for a large range of parameters the same conclusions emerge. If the incentives to fight internally are strong and the incentives to fight externally comparatively small, however, there will be internal fighting on the equilibrium path. Thus our article predicts that internal fighting will occur if two conditions are met: the insecurity of property within groups is high, and institutions are weak so that groups are unable to enforce decisions on external conflict.

Many historians argue that external wars were started out of consideration to internal conflict. For example, Kennedy (2000: 57) writes about the Great Arab Conquest, which started in the 7th century, that ".. the leadership had no choice but to direct the frenetic energies of the Bedouin against the Roman and Sasanian empires. The only way of avoiding an implosion was to direct the Muslim against the non-Muslim world." This example nicely fits our theoretical model-the leadership started external conquest, forseeing that otherwise internal conflict would arise. Other cases include the behavior of the military Junta in Argentina in the Falklands/Malvinas War (Levy and Vakili, 1992) or the German elites prior to World War I (Wehler, 1973; Joll, 1984). Moreover, large-scale ethnic violence is often seen as at least partially driven by political fighting within the elite of one ethnic group. For example, reviewing several case studies on inter-ethnic conflict, Fearon and Laitin (2000: 864) conclude that "the leader's motivation to "play the ethnic card' emerges out of political fighting within the leader's ethnic group". Cases in point include the genocide in Rwanda (Prunier, 1995; see also Hintjens, 1999), Sudan (Deng, 1995), and the Balkans (Woodward, 1995).

With our model, we also explicitly address several theoretical objections to the idea of diversionary wars. Blainey (1973) argues that any resources used in a war against outsiders could also be used to crush internal discord. We show that, nevertheless, players can be rational in starting a war against outsiders. Levy (1989, 1998) critically surveys the literature and asks for a more solid theory explicitly linking diversionary wars with the group cohesion effect. In this article, we try to answer his request by exposing a formal model that captures both the group cohesion effect and diversionary wars. Fearon and Laitin (2000) wonder why the public should follow if political leaders start a diversionary war. In our model, all individuals are perfectly rational and there is complete information but, nevertheless, individuals have an incentive to follow if some leader tries a diversionary tactic. This is in line with empirical observations: Fearon and Laitin (2000) conclude, based on their review of several case studies from diversionary conflict in inter-ethnic relations, that individuals have private benefits from following incitements to diversionary wars. For example, Woodward (1995: 249) argues that the war in Bosnia became, for many of the participants who sustained the violence, a "rare opportunity for enrichment, through theft and smuggling, in a period of economic decline. Early pictures in the war in Bosnia-Herzegovina show soldiers looting VCRs and stereos, urban furniture and appliances, and foreign automobiles such as BMWs". Similarly, Prunier (1995) attributes the 
genocide in Rwanda partially to internal fighting between moderate and extremist Hutu groups, and states that-in addition to indoctrination and obedience"[t]here was of course also an element of material interest in the killings [...]. The killers looted household belongings and slaughtered the cattle. Meat became very cheap, and grand feasts were held" (p. 248).

Existing formal models of diversionary wars usually rely on some kind of incomplete information. Hess and Orphanides (1995, 2001), Smith (1996), and Chapman and Reiter (2004) explain the occurrence of diversionary wars by the voters' incomplete information about the abilities of a leader. In contrast, we assume complete information and nevertheless find that diversionary wars are possible. Technically, our article is most closely related to the literature on the economics of conflict. Important contributions include Skaperdas (1992), Grossman (1991, 1994), and Hirschleifer (2001). See Garfinkel and Skaperdas (2007) for a survey. Münster (2007) studies simultaneous inter- and intra-group conflicts with a ratio form conflict technology. In contrast, we assume a logistic contest success function, which fits some stylized facts about warfare (see Hirshleifer, 1991). Moreover, unlike Münster (2007), we look at collective decisions concerning external conflict and in particular at the diversionary motive for external wars. A further difference is that in our model, the collective decisions on external conflict are taken before the individual decisions on internal conflict and production, which is more appropriate for modeling collective decisions on external conflict. Finally, we do not study the coalition formation of groups and group dynamics. See Garfinkel $(2004 a, b)$ on the formation of groups when there is a possibility of both internal and external conflict.

The article is organized as follows. Section 2 presents the basic model and section 3 studies its equilibria. Here we expose the group cohesion effect and the diversionary use of force. As a robustness check, section 4 looks at the case where decisions on external conflicts are taken individually. Section 5 concludes. The appendix collects most of the proofs.

\section{The Model}

There are $n$ identical individuals who are divided into $G$ groups of equal size $m=n / G$. Each individual is endowed with one unit of a resource, which can be used for three types of activities: production, external conflict (fighting against the outsiders), and internal conflict (fighting within one's own group). The amount of external conflict is chosen collectively by some political process. Since individuals are identical, members of a given group prefer the same amount of external conflict, given the behavior of competing groups, and we assume that this amount is chosen. Decisions on external fighting are made in the first stage of the game, before individuals decide how to allocate their remaining resources to internal fighting and production. Note that this time structure is consistent with, for example, what Kennedy (2007) writes about the Great Arab Conquest: when deciding on external conflict, groups take into account their likely impact on internal conflict. Denote production by individual $i$ in group $g$ by $e_{i g}$, internal fighting by $x_{i g}$, and the per capita 
amount of external fighting chosen by group $g$ by $y_{g}$. The resource constraint of the individual $i$ in group $g$ is ${ }^{1}$

$$
e_{i g}+x_{i g}+y_{g}=1
$$

Thus, we have the following two-stage game:

1. Each group decides on the amount $y_{g}$ that each group member has to put into the external conflict.

2. After observing all the decisions taken in stage 1, individuals simultaneously and independently decide how to allocate their remaining resources to production and internal fighting.

Total output depends on how much of the resource is devoted to production:

$$
q=f\left(\sum_{g=1}^{G} \sum_{i=1}^{m} e_{i g}\right)
$$

where $f$ is a production function satisfying $f(0)=0$ and $f^{\prime}(z)>0$ for all $z \geq 0$. In addition, we assume that $f$ is strictly log-concave. This is just a weak assumption: all concave functions, for example, are also log-concave. Log-concavity ensures that $f^{\prime}(z) / f(z)$ is strictly decreasing in $z$. Since this ratio plays a major role in the analysis that follows, we introduce the notation $\varnothing(z):=f^{\prime}(z) / f(z)$ for convenience.

The distribution of output depends on the fighting efforts. The share of output that goes to group $g$ is denoted by $p_{g}$ and is assumed to be a function of all the inter-group fighting activities. Thus, the amount that group $g$ gets is $p_{q} q$. From that amount, individual $i$ in group $g$ gets the share $r_{i g}$ which depends on the intra-group fighting activities of the members of group $g$. The payoff of individual $i$ in group $g$ is

$$
u_{i g}=r_{i g} p_{g} q
$$

In all models of conflict, one important modeling choice concerns the technology of conflict. The two most commonly studied technologies are the ratio form and the logistic technology of conflict. These two technologies have an axiomatic foundation by Skaperdas (1996), which can be extended to group contests (Münster, 2009). We focus on the logistic technology of conflict, since it fits some stylized facts about

\footnotetext{
${ }^{1}$ This resource constraint can, for example, be interpreted as a constraint on time. We normalize the resources available to an individual to 1 . Therefore, $x_{i g}$ (and similarly $y_{i g}$ and $e_{i g}$ ) can also be thought of as the fraction of resources invested in internal fighting (external fighting and production, respectively).
} 
warfare, as has been argued by Hirshleifer (1991). ${ }^{2}$ Individual $i$ in group $g$ gets the fraction

$$
r_{i g}=\frac{\exp \left(a x_{i g}\right)}{\sum_{j=1}^{\mathrm{m}} \exp \left(a x_{j g}\right)}
$$

The parameter $a>0$ describes the decisiveness of the intra-group contest. If $a$ is small, the fighting efforts will have little influence on the division of output, whereas if $a \rightarrow \infty$ then small differences in fighting efforts are decisive. We think of $a$ being determined by both technological factors (for example, police technology) and institutional factors pertaining to the security of property within a group. Similarly, group $g$ gets the fraction

$$
p_{g}=\frac{\exp \left(b m y_{g}\right)}{\sum_{k=1}^{G} \exp \left(b m y_{k}\right)} .
$$

The parameter $b>0$ describes the decisiveness of the inter-group contest and a smaller $b$ implies that fighting effort will have less influence on the division of output between groups. For example, a higher importance of international institutions and methods of peaceful international conflict resolution would mean that there is a lower incentive to engage in international fighting, which can be captured by a lower $b$ in our model. Like $a$, this is determined by technological and institutional factors. However, $b$ may differ from $a$ since both the technology and the relevant institutions differ in contests between groups from those in contests within groups. For example, a civil war (an intra-group conflict) is often fought with small arms, while in an international war (an inter-group conflict) heavy weapons like aircraft carriers may also be used.

\section{The Diversionary Use of Force}

We are interested in the subgame perfect equilibria and solve the game by backward induction. Substitute the budget constraints into the objective function to get $u_{i g}=r_{i g} p_{g} f\left(\sum_{k=1}^{G} \sum_{j=1}^{m}\left(1-x_{j k}-y_{k}\right)\right)$. In the second stage, individuals choose how to allocate their remaining resources between internal fighting and production. In their choices they are constrained by the amount of resources that has already been devoted to the external conflict in the first stage. Denote the objective function of individual $i$ in group $g$ in the second stage by $v_{i g}$; and let $x_{-i g}$ denote the vector of all the internal fighting efforts except $x_{i g}$. In stage 2, individual $i$ in group $g$ chooses $x_{i g}$ to maximize

\footnotetext{
${ }^{2}$ See Hirshleifer (2000) for further discussion of technologies of conflict. The logistic technology of conflict has also been used in Skaperdas and Syropoulos (1996), Baik (1998), and Anderton (2000).
} 


$$
v_{i g}\left(x_{i g}, x_{-i g} ; y_{1}, \ldots, y_{G}\right)=p_{g} \frac{\exp \left(a x_{i g}\right)}{\sum_{j=1}^{m} \exp \left(a x_{j g}\right)} f\left(\sum_{k=1}^{G} \sum_{j=1}^{m}\left(1-x_{j k}-y_{k}\right)\right)
$$

subject to $0 \leq x_{i g} \leq 1-y_{g}$.

It is straightforward to show that $v_{i g}$ is log-concave in $x_{i g}$. Moreover, the constraint set is convex. It follows that, in a solution, one of the following first-order conditions has to hold:

$$
\begin{gathered}
\frac{\partial v_{i g}}{\partial x_{i g}} \leq 0, x_{i g}=0 \text { or } \\
\frac{\partial v_{i g}}{\partial x_{i g}}=0, x_{i g} \in\left(0,1-y_{g}\right) \text { or } \\
\frac{\partial v_{i g}}{\partial x_{i g}} \geq 0, x_{i g}=1-y_{g} .
\end{gathered}
$$

Moreover, if one of these conditions holds, this is sufficient for a maximum. Line (2) concerns the case where the opportunity costs of internal fighting in terms of foregone production are prohibitively high and, thus, there is no internal fighting. Line (3) describes the case where there is an interior solution, where the amount of internal fighting is determined by the trade-off between internal fighting and production. Finally, the constraint that $x_{i g} \leq 1-y_{g}$ might be binding; line (4) takes this into account.

Calculating the derivative, we have

$$
\frac{\partial v_{i g}}{\partial x_{i g}}\left\{\begin{array}{l}
> \\
= \\
<
\end{array}\right\} 0 \Leftrightarrow \frac{a \sum_{j \neq i} \exp \left(a x_{j g}\right)}{\sum_{j=1}^{m} \exp \left(a x_{j g}\right)}\left\{\begin{array}{l}
> \\
= \\
<
\end{array}\right\} \phi\left(n-m \sum_{k=1}^{G} y_{k}-\sum_{k=1}^{G} \sum_{j=1}^{m} x_{j k}\right)
$$

where $\phi(z)=f^{\prime}(z) / f(z)$. Line (5) and the first-order conditions (2)-(4) imply the following lemma.

Lemma 1 Any equilibrium of the second stage is within-group symmetric: all players $i=1, \ldots, m$ in a given group $k$ choose the same $x_{i k}=x_{k}$. 
Conflict Management and Peace Science 28(2)

Using within-group symmetry, line (5) simplifies to

$$
\frac{\partial v_{i g}}{\partial x_{i g}}\left\{\begin{array}{l}
> \\
=
\end{array}\right\} 0 \Leftrightarrow \frac{a(m-1)}{m}\left\{\begin{array}{l}
> \\
= \\
<
\end{array}\right\} \phi\left(n-m \sum_{k=1}^{G}\left(y_{k}+x_{k}\right)\right) .
$$

If $a$ is below a certain threshold, which depends on the choices in the first stage, there is no internal fighting and only production in stage 2 . Lemma 2 specifies this. On the other hand, lemma 3 below shows that, if $a$ is bigger than the threshold, there is internal conflict.

\section{Lemma 2 If}

$$
\phi\left(n-m \sum_{k=1}^{G} y_{k}\right) \geq \frac{a(m-1)}{m},
$$

then there exists a unique equilibrium of the subgames in stage 2 with $x_{i g}=0$ for all individuals $i$ and groups $g$. Payoffs are

$$
u_{i g}=\frac{\exp \left(b m y_{g}\right)}{\sum_{k=1}^{G} \exp \left(b m y_{k}\right)} \frac{1}{m} f\left(n-m \sum_{k=1}^{G} y_{k}\right) .
$$

To gain some intuition, observe that (7) is likely to hold if there has been a lot of external fighting in stage 1 . Then there are few resources left over in stage 2 . Even if all the remaining resources are allocated to production, the marginal incentives to produce are higher than the marginal incentives to engage in internal conflict. Thus, there is no internal fighting.

Lemma 3 If inequality (7) does not hold, then in any equilibrium of the subgames in stage 2 there is internal fighting. The total amount of internal fighting is determined by

$$
\frac{a(m-1)}{m}=\phi\left(n-m \sum_{k=1}^{G}\left(y_{k}+x_{k}\right)\right) \text {. }
$$

Payoffs in all equilibria are

$$
u_{i g}=\frac{\exp \left(b m y_{g}\right)}{\sum_{k=1}^{G} \exp \left(b m y_{k}\right)} \frac{1}{m} f\left(\phi^{-1}\left(\frac{a(m-1)}{m}\right)\right)
$$


Lemma 3 describes the case where there was relatively little fighting in the first stage. Here, if all the remaining resources were allocated to production, the marginal incentives to fight internally would be higher than the marginal incentives to produce. Thus, there is some internal fighting in equilibrium, the amount being determined by the trade-off between internal fighting and production. Since expression (9) only determines the total amount of internal fighting, the equilibrium will typically be not unique. All equilibria, however, are payoff equivalent.

An interesting feature of the equilibrium utilities of the subgames in the second stage is that, in the case with internal fighting (lemma 3), equilibrium production does not depend on the choices made in the first stage. If there are more resources left over from the first stage, this simply leads to more internal conflict in the second stage. Conversely, increasing $y_{g}$ gives group $g$ a higher share $p_{g}$ of output without decreasing production. Of course this is no longer true once there is so much external fighting in stage 1 that (7) holds. Taken together, lemmas 2 and 3 offer a rationalist explanation of the group cohesion effect: when there is more external fighting, there will be less internal fighting.

We now consider the first stage.

Proposition 1 In any subgame perfect equilibrium, there is sufficient external fighting such that there is no internal fighting on the equilibrium path.

Proof Suppose to the contrary that there is internal fighting on the equilibrium path in a subgame perfect equilibrium. Denote the choices made in stage 1 in that supposed equilibrium by $\left(y_{1}^{*}, \ldots, y_{G}^{*}\right)$. By lemmas 2 and 3 , we have

$$
\phi\left(n-m \sum_{k=1}^{G} y_{k}^{*}\right)<\frac{a(m-1)}{m}
$$

and the utility of a member of group $g$ is

$$
u_{i g}=\frac{\exp \left(b m y_{g}^{*}\right)}{\sum_{k=1}^{G} \exp \left(b m y_{k}^{*}\right)} \frac{1}{m} f\left(\phi^{-1}\left(\frac{a(m-1)}{m}\right)\right) \text {. }
$$

Now suppose that instead of choosing $y_{g}^{*}$, group $g$ deviates to choose a higher amount of external fighting $y_{g}^{*}+\varepsilon$ in stage 1 , where $\varepsilon>0$ is sufficiently small such that

$$
\phi\left(n-m \sum_{k \neq g} y_{k}^{*}-m\left(y_{g}^{*}+\varepsilon\right)\right)<\frac{a(m-1)}{m} .
$$

By lemma 3, the resulting utility of members of group $g$ is

$$
\frac{\exp \left(b m y_{g}^{*}+\varepsilon\right)}{\exp \left(b m y_{g}^{*}+\varepsilon\right)+\sum_{k \neq g} \exp \left(b m y_{k}^{*}\right)} \frac{1}{m} f\left(\phi^{-1}\left(\frac{a(m-1)}{m}\right)\right)
$$


which is strictly higher than the supposed equilibrium utility given in (11). Hence, all individuals in group $g$ would prefer to choose a higher amount of external fighting in stage 1 . This shows that there can be no internal fighting on the equilibrium path.

The basic insight of this result is as follows. In stage 2 internal fighting can occur only if $\sum_{k=1}^{G} y_{k}$ is sufficiently small. Suppose this were the case and consider the decisions in stage 1. By lemma 3 the utility of each group $g$ is strictly increasing in $y_{g}$, as can be seen directly from equation (10). So each group would have an incentive to increase external fighting, at least up to the point where internal fighting ceases.

To analyze the equilibrium decisions on external conflict, the following definition of four separate cases is useful.

Definition 1 Let case $N O$ be defined by

$$
\phi(n) \geq \max \left\{b \frac{G-1}{G}, a \frac{m-1}{m}\right\}
$$

case INTRA by

$$
a \frac{m-1}{m}>\max \left\{b \frac{G-1}{G}, \phi(n)\right\}
$$

case INTER by

$$
b \frac{G-1}{G}>\max \left\{a \frac{m-1}{m}, \phi(n)\right\},
$$

and finally case SPECIAL by

$$
b \frac{G-1}{G}=a \frac{m-1}{m}>\phi(n) .
$$

Definition 1 is illustrated in Figure 1. The next proposition analyzes the equilibrium decisions at the first stage. We focus on the symmetric equilibrium where $y_{1}=\ldots=y_{G}=: y$.

Proposition 2 In the symmetric subgame perfect equilibrium, the choices of external fighting are as follows. In case NO, $y=0$. In case INTRA, y is given by

$$
\frac{a(m-1)}{m}=\phi(n(1-y)) .
$$




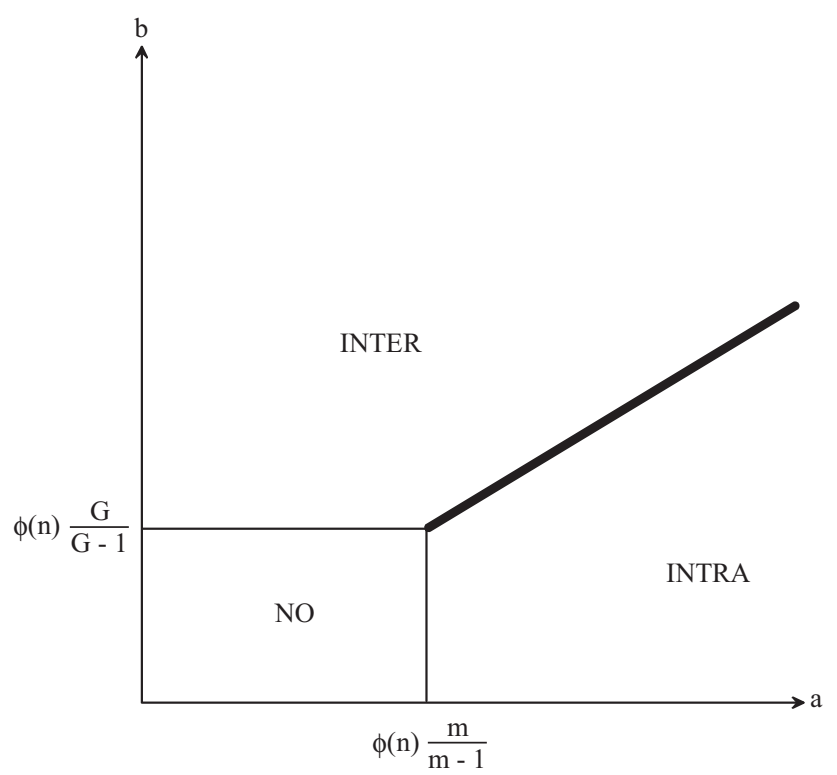

Figure 1. Here we illustrate the cases given in definition 1 . The bold line corresponds to case SPECIAL

In the cases INTER and SPECIAL, $y$ is given by

$$
\frac{b(G-1)}{G}=\phi(n(1-y)) .
$$

Proposition 2 shows that in case NO (where both $a$ and $b$ are relatively small) there will be no conflict at all. In case INTER (where $b$ is relatively big), the equilibrium amount of inter-group conflict will be determined by a trade-off between intergroup fighting and production. Given this amount of inter-group fighting, there is no internal conflict in stage 2 . The case INTRA (where $a$ is relatively big) is different, however. In this case, the equilibrium amount of external conflict is determined by the condition that there is no internal conflict in the second stage. That is, $\sum_{k=1}^{G} y_{k}$ is determined such that (7) holds with equality. How much external fighting occurs in case INTRA thus depends on the technology of internal conflict:

Corollary 1 In case INTRA, an increase in internal insecurity a leads to more external fighting $y$, while changes in external insecurity $b$ do not affect the amount of external fighting.

\section{Individual Decisions on External Conflict}

In this section, we study what happens if decisions on external conflict are taken individually, and groups cannot enforce collective decisions on external conflict. 
Let $y_{i g}$ denote the per capita amount of external fighting chosen by individual $i$ in group $g$. There are two stages:

1. Individuals simultaneously and independently choose $y_{i g} \in[0,1], i=1, \ldots, n$, $g=1, \ldots, G$.

2. After observing all choices at the first stage, individuals simultaneously and independently choose $x_{i g} \in\left[0,1-y_{i g}\right]$.

The share of output acquired by group $g$ equals

$$
p_{g}=\frac{\exp \left(b \sum_{j=1}^{m} y_{j g}\right)}{\sum_{k=1}^{G} \exp \left(b \sum_{j=1}^{m} y_{j k}\right)} .
$$

If $y_{j k}=y_{k}$ for all groups $k$ and all $j$ in group $k$, this is exactly equal to (1) above. In all other respects, the model is the same as above.

Proposition 3 In case INTRA, if

$$
a \frac{m-1}{m} \leq \phi\left(\frac{n}{n+1}\right)
$$

then the equilibrium path with collective decisions on external conflict is also an equilibrium path with individual decisions on external conflict.

Proposition 3 is a statement on the equilibrium path. The equilibria cannot be the same for the trivial reason that a strategy in the model with collective decisions is a different mathematical object than a strategy in the model with individual decisions. Proposition 3, however, shows that all observable behavior will be the same for a wide range of parameters. ${ }^{3}$

To see the logic behind proposition 3 , rewrite line (14) as

$$
1-\frac{1}{n} \phi^{-1}\left(a \frac{m-1}{m}\right) \leq \frac{n}{n+1} .
$$

The left-hand side of (15) equals the amount of external conflict chosen in stage 1 according to (12). If inequality (15) holds, the amount of external conflict is not extremely big. This means that, after an attempt to free-ride, the resources left over from stage 1 cannot differ too much. Hence, there exists an interior equilibrium in stage 2, where the players' shares within their groups are equal. A player who attempts to free-ride in the first stage has more resources available than the other players in stage 2. But he does not attain a higher utility: he ends up doing more

\footnotetext{
${ }^{3}$ It is straightforward to show that condition (14) is always satisfied unless more than $80 \%$ of the resources are invested in fighting.
} 
production in stage 2, but does not gain anything in terms of a higher share within his group. This is a paradox of power in the sense of Hirshleifer (1991). Total output is determined by the trade-off between internal fighting and production, and is thus the same as if there had been no deviation. So the deviation does not bring any benefit.

Proposition 3 shows that the possibility of diversionary wars does not crucially depend on the assumption that groups can force their members to invest a certain amount in external fighting. Rather, diversionary wars are possible even when all decisions are taken individually and noncooperatively. However, the similarity between the individual and collective decisions on external conflict breaks down if the incentives for internal fighting are extremely high.

Remark 1 Consider case INTRA. If a is sufficiently big, the equilibrium path with collective decisions on external conflict is not an equilibrium path with individual decisions on external conflict.

Therefore, the model predicts internal fighting whenever two conditions are met: property is very insecure within groups, and groups cannot enforce external fighting.

In contrast to case INTRA, the similarity between the two models holds without further assumptions in the other cases.

Proposition 4 In cases NO, INTER, and SPECIAL, the equilibrium path with individual decisions on external conflict is identical to the equilibrium path with collective decisions on external conflict.

This result is related to Skaperdas and Syropoulos (1997) who note the absence of a free-rider problem in a contest between two groups. In a classic free-rider problem, all share the benefits of some activities, but the costs are borne individually. In contrast, in the model considered here the cost of fighting against outsiders is foregone production and is thus borne by all players as well. If one player increases her $y_{i g}$, this not only has a positive externality on her fellow group members $\left(p_{g}\right.$ is higher), but also a negative externality ( $q$ is lower). This explains the absence of a free-rider problem.

\section{Conclusion}

This article studies the interdependence of internal conflict, external conflict, and production. We set up a model of conflict and appropriation where players are partitioned in groups and can engage in appropriation both against the other groups and within their own group. We distinguish between a technology of external conflict, which describes how easy or difficult it is to take from the other groups, and a technology of internal conflict, which describes the possibilities for appropriation within groups. These technologies may differ because the methods used in the two types of conflicts, as well as the institutions for conflict resolution, differ.

Decisions about external conflict are often taken by some political process. We therefore study collective decisions, where groups decide on the amount of resources that each group member has to devote to the external conflict, before 
individuals choose how to allocate their remaining resources to production and internal conflict. Groups choose sufficiently high external conflict in order to avoid internal conflict. Thus, there is no internal fighting on the equilibrium path. If property gets more insecure within groups, and hence incentives to start fighting internally are high, this only leads to more external fighting. That remains true even when groups cannot gain much from the other groups by fighting against them. In an extension we show that for a large range of parameter values similar results emerge when decisions on external fighting are taken individually. However, when property or power is very insecure within groups, and institutions are weak so that groups cannot force their members to invest resources into fighting against the outsiders, the model predicts that there will be internal fighting.

\section{A. Appendix}

Proof of Lemma 1 Suppose, to the contrary, that there are two individuals in the same group who choose different amounts of internal fighting. Without loss of generality, suppose $0 \leq x_{1 g}<x_{2 g} \leq 1-y_{g}$. Since $x_{1 g}<1-y_{g}$, from the first-order condition for player 1 (see lines (2) and (3)), we have

$$
\frac{a \sum_{j \neq 1} \exp \left(a x_{j g}\right)}{\sum_{j=1}^{m} \exp \left(a x_{j g}\right)} \leq \phi\left(n-m \sum_{k=1}^{G} y_{k}-\sum_{k=1}^{G} \sum_{j=1}^{m} x_{j k}\right) .
$$

On the other hand, since $0<x_{2 g}$, from the first-order conditions for player 2 (lines (3) and (4)) we get

$$
\phi\left(n-m \sum_{k=1}^{G} y_{k}-\sum_{k=1}^{G} \sum_{j=1}^{m} x_{j k}\right) \leq \frac{a \sum_{j \neq 2} \exp \left(a x_{j g}\right)}{\sum_{j=1}^{m} \exp \left(a x_{j g}\right)} .
$$

Putting things together, we have $\sum_{j \neq 1} \exp \left(a x_{j g}\right) \leq \sum_{j \neq 2} \exp \left(a x_{j g}\right)$ or $x_{1 g} \geq x_{2 g}$, a contradiction.

Proof of Lemma 2 Existence: The condition of the lemma (inequality (7)) implies that the first-order condition (2) for the case with no internal fighting holds for all individuals. Uniqueness: Suppose there exists an equilibrium where $x_{i g}>0$ for some individual $i$ in a group $g$. Then, by condition (7) of the lemma, and (6), we have $\frac{\partial v_{i g}}{\partial x_{i g}}<0$. This contradicts the first-order conditions (2)-(4). Payoffs follow by inserting.

Proof of Lemma 3 Existence: By (6), if equation (9) holds, we have $\partial v_{i g} / \partial x_{i g}=0$. It remains to show that there exist $x_{1}, \ldots, x_{G}$ such that $0 \leq x_{g} \leq 1-y_{g}$ for $g=1, \ldots, G$ and such that equation (9) holds. Note that if $x_{g}=1-y_{g}$ for all $g=1, \ldots, G$ we have

$$
\phi\left(n-m \sum_{k=1}^{G}\left(y_{k}+x_{k}\right)\right)=\phi(0)=\infty>\frac{a(m-1)}{m} .
$$


On the other hand, if $x_{g}=0$ for all $g=1, \ldots, G$ we have

$$
\phi\left(n-m \sum_{k=1}^{G}\left(y_{k}+x_{k}\right)\right)=\phi\left(n-m \sum_{k=1}^{G} y_{k}\right)<\frac{a(m-1)}{m}
$$

since by assumption inequality (7) does not hold. By continuity of $\phi$, there thus exist $x_{1}, \ldots, x_{G}$ such that $0 \leq x_{g} \leq 1-y_{g}$ for $g=1, \ldots, G$ and such that equation (9) holds. This completes the existence proof.

Uniqueness: Because of lemma 1 we only have to consider within-group symmetric equilibria. Equation (9) is equivalent to

$$
m \sum_{k=1}^{G} x_{k}=n-m \sum_{k=1}^{G} y_{k}-\phi^{-1}\left(a \frac{m-1}{m}\right)
$$

To ease notation, let $X:=n-m \sum_{k=1}^{G} y_{k}-\phi^{-1}(a(m-1) / m)$ denote the right-hand side of (16). Note that $X>0$ since, by assumption, (7) does not hold. Using the notation just introduced, (9) is equivalent to $m \sum_{k=1}^{G} x_{k}=X$. Moreover, by (6), (9) is also equivalent to $\frac{\partial v_{i g}}{\partial x_{i g}}=0$.

Suppose equation (9) does not hold. There are two possibilities. First, if $m \sum_{k=1}^{G} x_{k}<X$ we have $\frac{\partial v_{i g}}{\partial x_{i g}}>0$ by (6). Then the first order condition implies $x_{g}=1-y_{g}$ for all groups, hence $m \sum_{k=1}^{G} x_{k}=n-m \sum_{k=1}^{G} y_{k}>X$, contradicting the assumption $m \sum_{k=1}^{G} x_{k}<X$. Second, if $m \sum_{k=1}^{G} x_{k}<X$ we have $\frac{\partial v_{i g}}{\partial x_{i g}}<0$. Then the firstorder condition implies $x_{g}=0$ for all groups, and hence ${ }^{x_{i g}} m \sum_{k=1}^{G} x_{k}=0<X$, contradiction. Hence, there are no equilibria where (9) does not hold. Payoffs follow from inserting.

Proof of Proposition 2 Case NO Since $\phi(n) \geq a(m-1) / m$, inequality (7) holds for any possible $y_{1}, \ldots, y_{G}$. Hence in the second stage we have $x_{i g}=0$ for all $i$ and $g$, no matter what was chosen in stage 1 . Therefore in stage 1 the groups choose $y_{g} \in[0,1]$ to maximize

$$
u_{i g}=\frac{\exp \left(b m y_{g}\right)}{\sum_{k=1}^{G} \exp \left(b m y_{k}\right)} \frac{1}{m} f\left(n-m \sum_{k=1}^{G} y_{k}\right) .
$$

It is straightforward to show that $u_{i g}$ is log-concave in $y_{g}$. Moreover,

$$
\left.\frac{\partial u_{i g}}{\partial y_{g}}\right|_{y_{1}=\ldots=y_{G}=0}=\frac{b(G-1)}{G^{2}} f(n)-\frac{1}{G} f^{\prime}(n) \leq 0,
$$

since by definition of case NO, $b(G-1) / G \leq \phi(n)$. Since $u_{i g}$ is log-concave, it follows that there is an equilibrium where $y_{1}=\ldots=y_{G}=0$. Moreover, it is straightforward to show that the equilibrium is unique. 
Case INTRA Equation (12) defines a unique $y \in(0,1)$, namely

$$
y=1-\frac{1}{n} \phi^{-1}\left(\frac{a(m-1)}{m}\right) .
$$

Existence: If all groups choose $y_{g}=y$ given in (17), then in stage $2 x_{i g}=0$ for all $i$ and $g$. Fix all $y_{2}=\ldots=y_{G}=y$ and think of $u_{i 1}$ as a function of $y_{1}$. Choosing a $y_{1}<y$ leads to internal conflict in stage 2 , and is thus never optimal-in this range $u_{i 1}$ is strictly increasing in $y_{1}$ (see line (10) in lemma 3 ). On the other hand, if $y_{1} \in[y, 1]$ there is no internal fighting. In this range, the objective function $u_{i 1}$ is

$$
u_{i 1}=\frac{\exp \left(b m y_{1}\right)}{\exp \left(b m y_{1}\right)+(G-1) \exp (b m y)} \frac{1}{m} f\left(n-(G-1) m y-m y_{1}\right)
$$

(see line (8)). We will show that $u_{i 1}$ is strictly decreasing in $y_{1}$ for all $y_{1}>y$. For all $y_{1}>y$,

$$
\begin{aligned}
b \frac{(G-1) \exp (b m y)}{\exp \left(b m y_{1}\right)+(G-1) \exp (b m y)} & <b \frac{G-1}{G}<a \frac{m-1}{m} \\
& <\phi\left(n-(G-1) m y-m y_{1}\right)
\end{aligned}
$$

where the second inequality is from (INTRA), and the third inequality is from equation (12), $y_{1}>y$ and $\phi^{\prime}<0$. Hence for all $y_{1}>y$,

$$
b \frac{(G-1) \exp (b m y)}{\exp \left(b m y_{1}\right)+(G-1) \exp (b m y)}<\phi\left(n-(G-1) m y-m y_{1}\right),
$$

which by (18) is equivalent to $\partial u_{i 1} / \partial y_{1}<0$.

Uniqueness: Here we argue that there is no symmetric subgame perfect equilibrium where $y$ is not as given by (17). Suppose

$$
y<1-\frac{1}{n} \phi^{-1}\left(\frac{a(m-1)}{m}\right)
$$

Then we have internal fighting, contradiction. On the other hand, suppose

$$
y>1-\frac{1}{n} \phi^{-1}\left(\frac{a(m-1)}{m}\right) .
$$

Then we have $\phi(n(1-y))>a \frac{m-1}{m}>b \frac{G-1}{G}$. Hence each group would gain from choosing a slightly lower $y_{g}$-this still leads to zero internal conflict in the second stage, and the lower share of group $g$ is outweighed by the corresponding increase in output. 
Case INTER Existence:Equation (13) defines a unique $y \in(0,1)$. If $y_{1}=\ldots=y_{G}=y$ then we have $x_{i g}=0$ for all $i$ and $g$. Fix all $y_{g}=y, g=2, \ldots, G$ and think of $u_{i 1}$ as a function of $y_{1}$. Choosing a $y_{1}$ such that there is internal fighting can never be optimal. Moreover, among the range where there is no internal fighting, $u_{i g}$ is a strictly log-concave objective function to be maximized over a convex set, and at the proposed value the derivative of the objective function is zero.

Uniqueness: Here we argue that there is no symmetric subgame perfect equilibrium where $y$ is not given by equation (13). Suppose that $y<1-\frac{1}{n} \phi^{-1}\left(b \frac{G-1}{G}\right)$, then each group would profit from increasing $y_{g}$. On the other hand, if $y>1-\frac{1}{n} \phi^{-1}\left(b \frac{G-1}{G}\right)$, then each group would profit from decreasing its $y_{g}$.

Case SPECIAL Similar to case INTER.

Proof of Proposition 3 In stage 2, players are maximizing a continuous and quasiconcave objective function over a compact interval. By standard arguments, an equilibrium exists in all subgames.

If all players choose

$$
y_{i g}=y:=1-\frac{1}{n} \phi^{-1}\left(a \frac{m-1}{m}\right)
$$

in the first stage, then in the second stage all players have the same amount of resources left, and hence the analysis of the second stage of the model with collective decisions on external conflict applies. Thus, in stage 2 players have no incentive to deviate.

This implies that, in order to show existence of a subgame perfect Nash equilibrium with the desired properties, it is enough to analyze subgames that can be reached by a unilateral deviation in the first stage. Suppose all players except player $i=1$ in group $g=1$ choose $y_{j k}=y$ in stage 1 . We want to show that player $i=1$ in group $g=1$ has no incentive to deviate.

Consider a deviation to some $y_{11}>y$. Then, in the resulting subgame in stage 2 there is only production and zero internal fighting. The benefit of the deviation is a higher share $p_{1}$ for one's own group. However, it follows from the definition of case INTRA and (19) that this gain does not outweigh forgone production.

Thus, consider a deviation to some $y_{11}<y$. Then there is an equilibrium of the resulting subgame in stage 2 with the following properties: all players choose the same amount of internal fighting $x$ given by

$$
\phi\left(n-(n-1) y-y_{11}-n x\right)=a \frac{m-1}{m},
$$

and total productive effort is the same as on the proposed equilibrium path:

$$
\sum_{g=1}^{G} \sum_{i=1}^{m} e_{i g}=n-(n-1) y-y_{11}-n x=\phi^{-1}\left(a \frac{m-1}{m}\right) \text {. }
$$


To show this, we only have to show that there exists $x \in[0,1-y]$ such that (20) holds. To see that such an $x$ exists, note that if $x=0$, we have

$$
n-(n-1) y-y_{11}-n x=n-(n-1) y-y_{11} \geq n-n y
$$

since $y_{11}<y$. Thus $\phi\left(n-(n-1) y-y_{11}-n x\right) \leq \phi(n(1-y))=a \frac{m-1}{m}$. On the other hand, if $x=1-y$, then

$$
\begin{aligned}
& n-(n-1) y-y_{11}-n x=n-(n-1) y-y_{11}-n(1-y) \\
& \leq n-(n-1) y-n(1-y)=y \leq n(1-y) .
\end{aligned}
$$

The last inequality is by (15) (see the discussion of condition (15) in the main text). Thus, if $x=1-y$, then $\phi\left(n-(n-1) y-y_{11}-n x\right) \geq \phi(n(1-y))=a \frac{m-1}{m}$. By continuity of $\phi$, it follows that there exists an $x \in[0,1-y]$ such that (20) holds.

Now suppose that, after a deviation to a lower $y_{11}$, the players play the equilibrium of stage 2 just described. Then player 1 in group 1 gets an overall utility which is lower than if he had not deviated: $r_{11}=1 / m, q$ is the same as without a deviation, but $p_{1}$ is lower.

Proof of Remark 1 Consider case INTRA, fix some $b$, and let $a \rightarrow \infty$. Then, on the equilibrium path with collective decisions,

$$
u_{i g}=\frac{1}{n} f\left(\phi^{-1}\left(a \frac{m-1}{m}\right)\right) \rightarrow 0
$$

since $e=1-y=\phi^{-1}\left(a \frac{m-1}{m}\right) \rightarrow 0$. Now consider a deviation to $y_{11}=0$ and $x_{11}=\frac{1}{2}$. The worst that could happen to the deviating player is that no one else produces in stage 2 . Thus, his utility $\bar{u}$ is bigger or equal to

$$
\frac{\exp (b(m-1) y)}{\exp (b(m-1) y)+(G-1) \exp (b m y)} \frac{\exp \left(a \frac{1}{2}\right)}{\exp \left(\frac{a}{2}\right)+(m-1) \exp (a(1-y))} f\left(\frac{1}{2}\right)
$$

With $a \rightarrow \infty, y \rightarrow 1$. Moreover, the share $r_{11}$ that 11 gets within his group goes to 1:

$$
\frac{\exp \left(a \frac{1}{2}\right)}{\exp \left(a \frac{1}{2}\right)+(m-1) \exp (a(1-y))}=\frac{1}{1+(m-1) \exp \left(a\left(\frac{1}{2}-y\right)\right)} \rightarrow 1
$$

Hence

$$
\bar{u} \rightarrow \frac{\exp (b(m-1))}{\exp (b(m-1))+(G-1) \exp (b m)} f\left(\frac{1}{2}\right)>0 .
$$


Thus, for sufficiently high $a$, the deviation gives a higher utility.

Proof of Proposition 4 We only have to consider deviations in the first stage. Consider player $i=1$ in group $g=1$. Deviating to a higher amount of external fighting does not pay off: in the resulting subgame there is only production, and the gain in $p_{1}$ does not outweigh forgone production. Thus, consider a deviation to a lower $y_{11}$. This may have a strategic effect on the choices of the other players in the second stage. For the deviating player, the best that could possibly happen is that the other players use their remaining resources only for production in stage 2 , as on the proposed equilibrium path. Thus, the strategic effect can never be beneficial for the deviating player. Moreover, since at the proposed equilibrium values, $\partial u_{11} / \partial e_{11} \geq \partial u_{11} / \partial y_{11} \geq \partial u_{11} / \partial x_{11}$ the deviation does not pay off, even if it has no influence in the second-stage choices of the other players.

\section{References}

Anderton, C. H. 2000. An insecure economy under ratio and logistic conflict technologies. Journal of Conflict Resolution 44(6): 823-838.

Baik, K. H. 1998. Difference-form contest success functions and effort levels in contests. European Journal of Political Economy 14(4): 685-701.

Blainey, G. 1973. The Causes of War. New York: Free Press.

Chapman, T., and D. Reiter. 2004. The United Nations Security Council and the rally 'round the flag effect. Journal of Conflict Resolution 48(6): 886-909.

Deng, F. M. 1995. War of Visions: Conflict of Identities in the Sudan. Washington, DC: Brookings Institution.

Fearon, J. D., and D. D. Laitin. 2000. Violence and the social construction of ethnic violence. International Organization 54(4): 845-877.

Garfinkel, M. 2004a. On the stability of group formation: Managing the conflict within. Conflict Management and Peace Science 21(1): 1-26.

Garfinkel, M. 2004b. Stable alliance formation in distributional conflict. European Journal of Political Economy 20(4): 829-852.

Garfinkel, M., and S. Skaperdas. 2007. Economics of conflict: An overview. In Handbook of Defense Economics, Vol. 2, eds T. Sandler and K. Hartley, ch. 22. Amsterdam: North Holland.

Grossman, H. I. 1991. A general equilibrium model of insurrections. American Economic Review 81(4): 912-921.

Grossman, H. I. 1994. Production, appropriation, and land reform. American Economic Review 84(3): 705-712.

Hess, G. D., and A. Orphanides. 1995. War politics: An economic, rational-voter framework. American Economic Review 85(4): 828-846.

Hess, G. D., and A. Orphanides. 2001. War and democracy. Journal of Political Economics 100(4): 776-810.

Hintjens, H. M. 1999. Explaining the 1994 genocide in Rwanda. Journal of Modern African Studies 37: 241-286.

Hirshleifer, J. 1991. The technology of conflict as an economic activity. American Economic Review 81(2): 130-134.

Hirshleifer, J. 2000. The macrotechnology of conflict. Journal of Conflict Resolution 44(6): 773-792.

Hirshleifer, J. 2001. The Dark Side of the Force. Cambridge: Cambridge University Press. 


\section{Conflict Management and Peace Science 28(2)}

Joll, J. 1984. The Origins of the First World War. London: Longman.

Kennedy, H. 2007. The Great Arab Conquests: How the Spread of Islam Changed the World We Live In. London: Weidenfeld \& Nicolson.

Levy, J. S. 1989. The diversionary theory of war: A critique. In Handbook of War Studies, ed. M. I. Midlarsky. Boston: Unwin Hyman.

Levy, J. S. 1998. The causes of war and the conditions of peace. Annual Review of Political Science 1: 139-165.

Levy, J. S., and L. I. Vakili. 1992. Diversionary action by authoritarian regimes: Argentina in the Falklands/Malvinas case. In The Internationalization of Communal Strife, ed. M. I. Midlarsky, pp. 118-146. London and New York: Routledge.

Münster, J. 2007. Simultaneous inter- and intra-group conflicts. Economic Theory 32(3): 333-352.

Münster, J. 2009. Group contest success functions. Economic Theory 41(2): 345-357.

Prunier, G. 1995. The Rwanda Crisis: History of a Genocide. New York: Columbia University Press.

Skaperdas, S. 1992. Cooperation, conflict, and power in the absence of property rights. American Economic Review 82(4): 720-739.

Skaperdas, S. 1996. Contest success functions. Economic Theory 7(2): 283-290.

Skaperdas, S. and Syropoulos, C. 1996. Can the shadow of the future harm cooperation? Journal of Economic Behavior and Organization 29(3): 355-372.

Skaperdas, S., and Syropoulos, C. 1997. The distribution of income in the presence of appropriative activities. Economica 64: 101-117.

Smith, A. 1996. Diversionary foreign policy in democratic systems. International Studies Quarterly 40(1): 133-153.

Sumner, W. G. 1906. Folkways, cited following the Arno Press New York 1979 edition.

Wehler, H.-U. 1973. Das Deutsche Kaiserreich 1871-1918. Göttingen: Vandenhoeck u. Ruprecht.

Woodward, S. L. 1995. Balkan Tragedy: Chaos and Dissolution after the Cold War. Washington, DC: Brookings Institution.

JOHANNES MÜNSTER is assistant professor at the Free University of Berlin. He works on microeconomic theory and political economics. His research has been published in Games and Economic Behavior, Economic Theory, Journal of Economics \& Management Strategy, and other refereed journals.

KLAAS STAAL is a postdoctoral fellow at the Institute for International Economic Policy in Bonn. His scientific interests are in political economics, peace science and public economics. His research has been published in the European Economic Review, Public Choice, and International Advances in Economic Research, among others. 